\title{
Long-term results of aortic root repair using the reimplantation technique
}

\author{
Tirone E. David, MD, Susan Armstrong, MSc, Cedric Manlhiot, BSc, Brian W. McCrindle, MD, MPH, and \\ Christopher M. Feindel, MD
}

\begin{abstract}
Objectives: Aortic valve sparing is frequently performed to treat patients with aortic root aneurysm, but there is an inadequate amount of information regarding its long-term durability. This study examines the long-term results of reimplantation of the aortic valve in patients with aortic root aneurysms.
\end{abstract}

\begin{abstract}
Methods: From August 1989 to December 2010, 296 consecutive patients had reimplantation of the aortic valve into a tubular Dacron graft. Their mean age was 45 years (range, $11-79$ years), and $78 \%$ were men. Of the patients, 36\% had Marfan syndrome and $11 \%$ had bicuspid aortic valve. Patients were followed prospectively with periodic images of the aortic root and remaining aorta. The mean follow-up was $6.9 \pm 4.5$ years. There were 21 patients at risk at 15 years.
\end{abstract}

Results: There were 4 operative and 18 late deaths. The survival at 5, 10, and 15 years was $95.1 \% \pm 3.5 \%$, $93.1 \% \pm 4.4 \%$, and $76.5 \% \pm 18 \%$, respectively. Only 3 patients required reoperation on the aortic valve; all 3 patients had the Bentall procedure. Freedom from reoperation at 5, 10, and 15 years was $99.7 \% \pm 2.0 \%$, $97.8 \% \pm 5.3 \%$, and $97.8 \% \pm 5.3 \%$, respectively. During follow-up, moderate aortic insufficiency developed in 9 patients, and severe aortic insufficiency developed in 2 patients. Freedom from moderate or severe aortic insufficiency at 5,10 , and 15 years was $98.3 \% \pm 3.5 \%, 92.9 \% \pm 6.5 \%$, and $89.4 \% \pm 12 \%$, respectively.

Conclusions: The function of the aortic valve implanted inside a tubular Dacron graft remains normal at 15 years in most patients after this type of aortic valve-sparing operation. (J Thorac Cardiovasc Surg 2013;145:S22-5)

Aortic valve-sparing operations were developed to preserve the aortic valve cusps of patients with aortic root aneurysm with or without aortic insufficiency (AI). ${ }^{1,2}$ There are basically 2 basic types of aortic valve-sparing operations: reimplantation of the aortic valve and remodeling of the aortic root. ${ }^{1-3}$ Although remodeling of the aortic root is physiologically superior to reimplantation of the aortic valve, ${ }^{4}$ it does not correct the problem of dilation of the aortic annulus that often occurs in young patients with inherited connective tissue disorders of the aortic root, such as Marfan syndrome. Remodeling of the aortic root in these patients is associated with a higher risk of developing late $\mathrm{AI}^{5,6}$

This report summarizes the long-term results of aortic root repair using the reimplantation technique at the Peter Munk Cardiac Centre during the past 2 decades. Our patients have been followed prospectively with periodic images of the aortic root, heart, and great vessels.

From the Division of Cardiovascular Surgery of Peter Munk Cardiac Centre at Toronto General Hospital and the University of Toronto, Toronto, Ontario, Canada.

Disclosures: Drs David, Armstrong, Manlhiot, McCrindle, and Feindel have nothing to disclose with regard to commercial support.

Read at The American Association for Thoracic Surgery Aortic Symposium, New York, New York, April 26-27, 2012.

Received for publication May 9, 2012; revisions received Aug 2, 2012; accepted for publication Nov 28, 2012; available ahead of print Dec 20, 2012.

Address for reprints: Tirone E. David, MD, 200 Elizabeth St 4N453, Toronto, Ontario M5G 2C5, Canada (E-mail: tirone.david@uhn.ca).

$0022-5223 / \$ 36.00$

Copyright (c) 2013 by The American Association for Thoracic Surgery

http://dx.doi.org/10.1016/j.jtcvs.2012.11.075

\section{PATIENTS AND METHODS}

From August 1989 to December 2010, 296 consecutive patients with aortic root aneurysm had reimplantation of the aortic valve into a tubular Dacron graft. The operative techniques used have been described in detail in recent publications. ${ }^{7,8}$ The first 89 patients had the aortic valve reimplanted into a straight tubular Dacron graft. In the mid-1990s, it became apparent that the lack of aortic sinuses was associated with increased opening and closing velocities of the aortic cusps, and one of the authors (T.E.D.) began to use larger grafts than needed and plicated the graft to create neoaortic sinuses. ${ }^{7,8}$ A total of 118 patients had neoaortic sinuses created in this series. Patients were anticoagulated with warfarin sodium if they had concomitant mitral valve repair or developed atrial fibrillation postoperatively; otherwise, they were prescribed only aspirin.

Table 1 summarizes the preoperative data of these patients; Table 2 describes the operative data. Patients had annual transthoracic echocardiographic studies to assess aortic valve function during the first 5 years, and if there was no important dysfunction, they were assessed every second year thereafter. Computed tomography and magnetic resonance images of the entire thoracic aorta were obtained every 5 years or more often when appropriate. The clinical follow-up extended from 0 to 22.1 years, with a mean of $6.9 \pm 4.5$ years. The follow-up was closed on February 29, 2012, for this report. There were 21 patients at risk at 15 years. This study was approved by the Review Ethic Board of University Health Network.

All data statistical analyses were performed with SAS 9.3 software (SAS Institute, Inc, Cary, NC). Categoric variables are reported as frequencies, and all continuous variables are reported as mean \pm standard deviation. The Kaplan-Meier method was used to calculate estimates for long-term survival or freedom from morbid events; values are shown as means and standard errors of the means. All preoperative variables with a univariate $P$ value of less than .25 or those with known biologic significance but failing to meet this critical level were tested in a multivariable modeling Cox proportional hazard regression analysis to determine the 


\section{Abbreviation and Acronym \\ $\mathrm{AI}=$ aortic insufficiency}

independent predictors of postoperative AI. Variable retention criteria in the multivariable model were set at a $P$ value of .05 .

\section{RESULTS}

There were 4 deaths during the first 90 days after repair. The causes of early deaths included stroke in 1 patient at home 6 weeks after surgery, low cardiac output syndrome in 1 patient, acute type B aortic dissection with profound lower body ischemia on the day after surgery in 1 patient with Marfan syndrome (there was no evidence of dissection in the intraoperative echocardiogram), and Clostridium difficile colitis in 1 patient while in a convalescence hospital 3 weeks after surgery. Reexploration of the mediastinum for bleeding or tamponade was performed in 26 patients $(8.7 \%)$. Two patients had early reoperations, 1 for refractory ventricular fibrillation due to myocardial ischemia and 1 for AI. Both patients survived, but 1 required aortic valve replacement. Four patients had a perioperative myocardial infarction, 3 patients had implantation of a permanent transvenous pacemaker, renal failure requiring temporary dialysis developed in 2 patients, 1 patient had a deep sternal infection, and 3 patients had superficial wound infections. Assisted ventilation for more than 24 hours was noted in 30 patients (none required tracheostomy). In addition, transient new atrial fibrillation developed in 64 patients $(21.6 \%)$.

There were 18 late deaths: 4 sudden, 6 due to complications of aortic dissection, 2 due to myocardial infarction, 2 due to heart and renal failure, and 4 noncardiovascularrelated. Aortic dissection, mitral valve disease, left ventricular ejection fraction less than $40 \%$, New York Heart Association functional class IV, congestive heart failure, cardiopulmonary bypass and operating times, and urgent/ emergency surgery were associated with increased risk of death from any cause by univariate analysis but not by multivariable analysis. Survival at $1,5,10$, and 15 years was $97.6 \% \pm 2.6 \%, 95.1 \% \pm 3.5 \%, 93.1 \% \pm 4.4 \%$, and $76.5 \% \pm 18 \%$, respectively.

Infective endocarditis of the mitral valve developed in 2 patients, and both were successfully treated with antibiotics, but 1 required mitral valve repair because of severe mitral regurgitation. Including perioperative events, 6 patients had thromboembolic complications: 2 strokes and 4 transient ischemic attacks. One of the patients who had a stroke had undergone a total arch replacement and died 3 weeks after surgery; the second patient had a chronic type A dissection with intimal tears in the aortic arch and recovered completely. Twenty-four patients were taking oral anticoagulation because of previous thromboembolic complications or atrial fibrillation, and 4 of them had major hemorrhagic complications, but none of these events was fatal.

Three patients required reoperation on the aortic valve all for AI. The second patient ever to have reimplantation of the aortic valve was left with moderate AI, and we decided to replace his aortic valve on the second postoperative day. The other 2 patients underwent reoperation 6 and 9 years later. All 3 patients had replacement of the aortic root because the annulus was too small for the patients' sizes to have implanted an aortic valve inside the reconstructed root. The freedom from reoperation on the aortic valve at $1,5,10$, and 15 years was $99.7 \% \pm 2.0 \%$, $99.7 \% \pm 2.0 \%, 97.8 \% \pm 5.3 \%$, and $97.8 \% \pm 5.3 \%$, respectively (Figure 1). In addition to reoperations on the aortic valve, 2 patients had mitral valve repair, 2 patients had replacement of the thoracoabdominal aorta, 1 patient had repair of an abdominal aortic aneurysm, and 1 patient had coronary artery bypass grafting.

During follow-up, moderate AI developed in 9 patients, and severe AI developed in 2 patients. Four of the 11 patients had a bicuspid aortic valve. The number of patients with bicuspid aortic valves was too small for meaningful comparison with tricuspid aortic valves. Age by increments of 5 years, bicuspid aortic valve, and hypertension were associated with an increased risk of developing moderate or severe AI by univariate analysis. Severe AI before surgery, cusp plication, cusp reinforcement with expanded polytetrafluoroethylene suture, and creation of neoaortic sinuses had no effect on postoperative AI by univariate analysis. However, Marfan syndrome emerged as protective against the development of AI by Cox regression analysis (hazard ratio, $0.167 ; P=.017)$. The freedom from moderate or severe $\mathrm{AI}$ in all patients at $1,5,10$, and 15 years was $99.6 \% \pm 0.8 \%, 98.3 \% \pm 3.5 \%, 92.9 \% \pm 6.5 \%$, and $89.4 \% \pm 12 \%$, respectively (Figure 2). At the time of the last follow-up contact, $82 \%$ of patients were in New York Heart Association functional class I, 13\% were in class II, and $5 \%$ were in class III.

\section{DISCUSSION}

Aortic valve function after aortic valve sparing using the reimplantation of the aortic valve continues to demonstrate excellent results up to 15 years of follow-up. However, as with mitral valve repair for degenerative diseases, ${ }^{9}$ surgery does not arrest the degenerative process and aortic valve function may deteriorate with time. Given that most patients with aortic root aneurysms are relatively young, these operations are probably the best option if permanent oral anticoagulation is not desirable, but patients have to be informed that reoperation may become necessary in the future. However, one has to consider that freedom from reoperation on the aortic valve at 15 years was $97.8 \% \pm 5.3 \%$, and the 
TABLE 1. Preoperative data

\begin{tabular}{|c|c|}
\hline No. of patients & 296 \\
\hline Mean age $\pm \mathrm{SD}, \mathrm{y}$ & $46.3 \pm 15.0$ \\
\hline Range & $11-79$ \\
\hline Body surface area $\left(\mathrm{m}^{2} \pm \mathrm{SD}\right)$ & $2.04 \pm 0.26$ \\
\hline Sex: male & $231(78)$ \\
\hline \multicolumn{2}{|l|}{ Presenting symptoms } \\
\hline Heart failure & $22(7.4)$ \\
\hline Chest pain & $19(6.4)$ \\
\hline Syncope & $7(2.3)$ \\
\hline Shock & $2(0.6)$ \\
\hline \multicolumn{2}{|l|}{ Associated diseases } \\
\hline Marfan syndrome & $106(35.8)$ \\
\hline Diabetes & $9(3)$ \\
\hline Hypertension & $115(38.8)$ \\
\hline Hyperlipidemia & $63(21.2)$ \\
\hline $\mathrm{COPD}\left(\mathrm{FEV}_{1}<1\right)$ & $7(2.3)$ \\
\hline Previous stroke & $7(2.3)$ \\
\hline Peripheral vascular disease & $5(1.6)$ \\
\hline Renal failure on hemodialysis & $4(1.3)$ \\
\hline \multicolumn{2}{|l|}{ Timing of surgery } \\
\hline Urgent/emergency & $25(8.4)$ \\
\hline \multicolumn{2}{|l|}{ New York Heart Association } \\
\hline Class I & $175(59.1)$ \\
\hline Class II & $76(25.6)$ \\
\hline Class III & $19(6.4)$ \\
\hline Class IV & $26(8.7)$ \\
\hline Previous replacement of ascending aorta & $4(1.3)$ \\
\hline Previous cardiac operation & $14(4.7)$ \\
\hline \multicolumn{2}{|l|}{ Cardiac rhythm } \\
\hline Sinus rhythm & $288(97.2)$ \\
\hline Atrial fibrillation & $7(2.3)$ \\
\hline Complete heart block & $1(0.3)$ \\
\hline \multicolumn{2}{|l|}{ Left ventricular ejection fraction } \\
\hline$>40 \%$ & $274(92.5)$ \\
\hline$\leq 40 \%$ & $21(7)$ \\
\hline Unknown & $1(0.3)$ \\
\hline Coronary artery disease & $29(9.7)$ \\
\hline \multicolumn{2}{|l|}{ Aortic valve pathology } \\
\hline Bicuspid aortic valve & $32(10.8)$ \\
\hline \multicolumn{2}{|l|}{ Tricuspid aortic valve } \\
\hline Annulo-aortic ectasia & $198(66.8)$ \\
\hline Dissected sinuses & $16(5.4)$ \\
\hline Normal valve and annulus & $53(18)$ \\
\hline \multicolumn{2}{|l|}{ Type A aortic dissection } \\
\hline Acute & $19(6.4)$ \\
\hline Chronic & $6(2)$ \\
\hline Arch aneurysm & $55(15)$ \\
\hline Mitral regurgitation & $25(8.4)$ \\
\hline \multicolumn{2}{|l|}{ Aortic regurgitation } \\
\hline None/trace & $62(21)$ \\
\hline Mild & $83(28)$ \\
\hline Moderate & $77(22)$ \\
\hline Severe & $63(21.2)$ \\
\hline Unknown & $11(3.7)$ \\
\hline
\end{tabular}

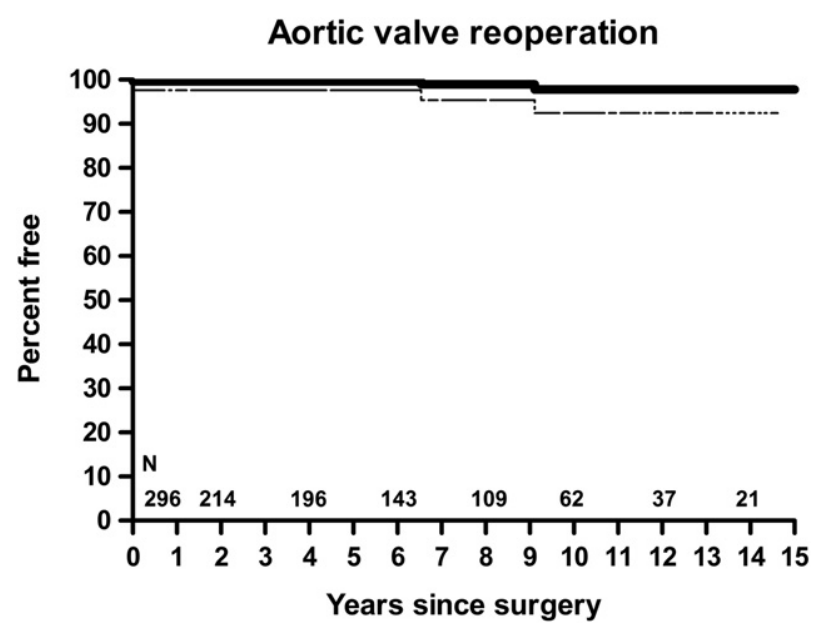

FIGURE 1. Freedom from reoperation on the aortic valve.

freedom from recurrent moderate or severe AI was $89.4 \% \pm 12 \%$. These estimates of time-related freedom from valve-related complications are certainly superior to those obtained with bioprosthetic or biological valve in young adults.

As with any reconstructive procedure, these operations must be performed with intraoperative echocardiography to assess valve morphology and function at the end of the procedure. Restoration of normal aortic cusp geometry is the single most important technical aspect of aortic valvesparing operations. In addition to having a competent valve with no or only minimal central AI at the end of the procedure, no cusp should be prolapsing, and the coaptation height has to be well above the level of the nadir of the aortic annulus. ${ }^{10}$ Finally, patient selection also is important. Patients with severe AI before surgery often have damaged cusps and are not good candidates for this operation. Most of our patients had normal or near-normal cusps on gross inspection, but after the reimplantation, 1 or more cusps

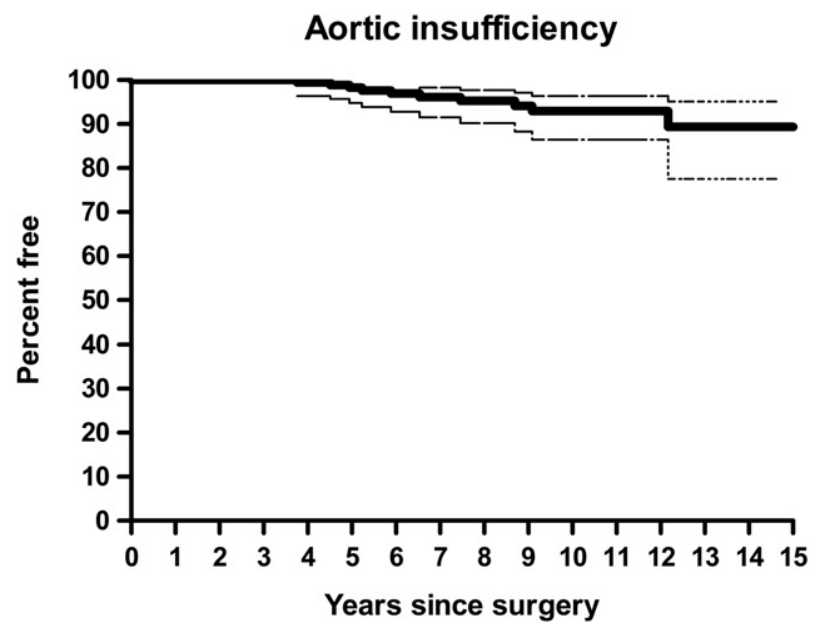

FIGURE 2. Freedom from moderate or severe AI. 


\section{TABLE 2. Operative data}

\begin{tabular}{lc}
\hline Reimplantation of the aortic valve & $296(79)$ \\
Size of graft for reimplantation \pm SD & $31.5 \pm 2.4 \mathrm{~mm}$ \\
Plication of free margin of aortic cusps: & \\
$\quad 1$ cusp & $81(27.3)$ \\
2 cusps & $27(9.1)$ \\
3 cusps & $15(5)$ \\
Reinforcement of free margin with ePTFE suture & $68(23)$ \\
Creation of neoaortic sinuses during reimplantation & $115(38.8)$ \\
Replacement of aortic arch or hemiarch & $59(20)$ \\
MV repair & $24(8)$ \\
MV replacement with reconstruction of calcified annulus & $1(0.3)$ \\
Coronary artery bypass graft & $32(10.8)$ \\
Atrial septal defect closure & $15(5)$ \\
Ventricular septal defect closure & $2(0.6)$ \\
Maze procedure for atrial fibrillation & $4(1.3)$ \\
Repair of abdominal aortic aneurysm & $1(0.3)$ \\
Mean aortic clamp time \pm SD, min & $117 \pm 326$ \\
Mean CPB \pm SD, min & $141 \pm 32$ \\
\hline Percentages are shown in parentheses. SD, Standard deviation; $e P T F E$, expanded \\
polytetrafluoroethylene; $M V$, mitral valve; $C P B$, cardiopulmonary bypass.
\end{tabular}

appeared to be prolapsing and plication along the nodule of Arantius was necessary to allow for proper coaptation. We have shown that repair of cusp prolapse, either by plication of its central portion or with a double layer of a fine expanded polytetrafluoroethylene suture along the free margin, was not associated with an increased risk of developing late $\mathrm{AI}^{7}$

The issue of repairing the incompetent bicuspid aortic valve is a complex one and highly dependent on patient selection. ${ }^{10,11}$ These valves are often associated with annulo-aortic ectasia, and some investigators believe that reimplantation of the aortic valve reduces the risk of late AI. ${ }^{11}$ Also important is the quality of the cusps when the operation is performed. Thin, pliable, elastic cusps can be repaired, particularly if there is no raphe or the cusp with a raphe has a size similar to the normal cusp. Longer follow-up is needed to determine the appropriateness of aortic valve-sparing operations in patients with bicuspid aortic valve and a dilated aortic root.

Although reimplantation of the aortic valve has been successfully performed in patients with acute type A aortic dissection, ${ }^{12}$ it is important to consider that surgery for acute type A aortic dissection remains associated with high operative mortality and morbidity, and adding a long and complex operative procedure in the aortic root (eg, an aortic valve sparing) may not be the safest approach. In our experience with 19 patients, there was no operative death, but 6 patients died late of complications related to the false lumen.

Patients with Marfan syndrome seemed to have more stable valve function than others, but they were also younger. In a previous analysis of our entire patient population of aortic valve-sparing operations, we found that age had a protective effect on freedom from developing late $\mathrm{AI}^{7}{ }^{7}$ It is possible that cusps from younger patients have better adaptability to a rigid structure (eg, a tubular Dacron graft) than the cusps of older patients. It has been postulated that a rigid aortic root may accelerate degenerative changes in the aortic cusps. ${ }^{13}$

\section{Study Limitations}

This study has several limitations largely because it is retrospective and we have had few adverse advents. In addition, the number of patients in some subgroups (eg, those with bicuspid aortic valve, dissecting aneurysms, coronary artery disease, and mitral insufficiency) is relatively small for meaningful multivariable analysis.

\section{CONCLUSIONS}

Reimplantation of the aortic valve has provided excellent aortic valve function during the first 15 years of follow-up. The rates of valve-related complications are low, and certainly lower than those obtained with bioprosthetic and biological valves, making this operation an ideal alternative to placement of mechanical valves in patients with aortic root aneurysm when permanent oral anticoagulation is undesirable.

\section{References}

1. David TE, Feindel CM. An aortic valve-sparing operation for patients with aortic incompetence and aneurysm of the ascending aorta. J Thorac Cardiovasc Surg. 1992;103:617-22

2. Yacoub MH, Gehle P, Chandrasekaran V, Birks EJ, Child A, Radley-Smith R Late results of a valve-preserving operation in patients with aneurysms of the ascending aorta and root. $J$ Thorac Cardiovasc Surg. 1998;115:1080-90.

3. David TE, Feindel CM, Bos J. Repair of the aortic valve in patients with aortic insufficiency and aortic root aneurysm. J Thorac Cardiovasc Surg. 1995;109: 345-52.

4. Leyh RG, Schmidtke C, Sievers HH, Yacoub MH. Opening and closing characteristics of the aortic valve after different types of valve-preserving surgery. Circulation. 1999;100:2152-60.

5. Birks EJ, Webb C, Child A, Radley-Smith R, Yacoub MH. Early and long-term results of a valve-sparing operation for Marfan syndrome. Circulation. 1999 100(19 Suppl):II29-35.

6. David TE, Armstrong S, Maganti M, Colman J, Bradley TJ. Long-term results of aortic valve-sparing operations in patients with Marfan syndrome. $J$ Thorac Cardiovasc Surg. 2009;138:859-64.

7. David TE, Maganti M, Armstrong S. Aortic root aneurysm: principles of repai and long-term follow-up. J Thorac Cardiovasc Surg. 2010;140:S14-9.

8. David TE. How I do aortic valve sparing operations to treat aortic root aneurysm. J Cardiac Surg. 2011;26:92-9.

9. David TE, Ivanov J, Armstrong S, Christie D, Rakowski H. A comparison of outcomes of mitral valve repair for degenerative disease with posterior, anterior, and bileaflet prolapse. J Thorac Cardiovasc Surg. 2005;130:1242-9.

10. Kunihara T, Aicher D, Rodionycheva S, Groesdonk HV, Langer F, Sata F, et al. Preoperative aortic root geometry and postoperative cusp configuration primarily determine long-term outcome after valve-preserving aortic root repair. $J$ Thorac Cardiovasc Surg. 2011 Aug 18. [Epub ahead of print]

11. de Kerchove L, Boodhwani M, Glineur D, Vandyck M, Vanoverschelde JL, Noirhomme P, et al. Valve sparing-root replacement with the reimplantation technique to increase the durability of bicuspid aortic valve repair. $J$ Thorac Cardiovasc Surg. 2011;142:1430-8.

12. Leyh RG, Fischer S, Kallenbach K, Kofidis T, Pethig K, Harringer W, et al. High failure rate after valve-sparing aortic root replacement using the "remodeling technique" in acute type A aortic dissection. Circulation. 2002;106(12 Suppl 1):I229-33.

13. Fokin AA, Robicsek F, Cook JW, Thubrikar MJ, Schaper J. Morphological changes of the aortic valve leaflets in non-compliant aortic roots: in-vivo experiments. J Heart Valve Dis. 2004;13:444-51. 